Maja Đurinović

Akademija za umjetnost i kulturu u Osijeku

maja.durinovic1@gmail.com

(D) https://orcid.org/0000-0002-8194-5932

\title{
Postdramsko čitanje Krleže: rad s mladom glumicom i plesačicom Selmom Mehić na autorskom projektu - monokoreodrami Krležina Saloma / Rekvijem za mladog umjetnika
}

\author{
Postdramatic reading of Krleža: working with a young actress \\ and dance performer Selma Mehić on the authorial project - \\ mono-choreodrama Krleža's Salome / Requiem for a Young Artist
}

Sažetak: Rad objedinjuje dugogodišnje istraživanje odnosa tjelesnog, scenskog pokreta i pjesničkog teksta i iskustvo konkretnog mentorskog i koautorskog rada na formi monokoreodrame. Autorski je projekt potaknut kulturološkom temom plesačice Salome, a onda i dramskim likom iz istoimene dramske legende Miroslava Krleže, kao i dugogodišnjim zanimanjem za, u jugoslavenskoj kulturnoj javnosti, potisnuti dio opusa znamenitog pisca. Istraživanje je uključivalo analizu književno-teoretske recepcije drame, usporedbu i odabir dijelova Salomina teksta iz Krležinih inačica sačuvanih u rukopisima, pri čemu se formirala dramaturški samostalna autorska cjelina teksta i paralelno - praktičnu primjenu u dvorani, kroz proces tjelesnog usvajanja i preoblikovanja materijala.

Ključne riječi: Miroslav Krleža, Saloma, rječita plesačica, tijelo, zvijezde

Summary: The work incorporates a long-standing research of the relation among the body, stage movement and poetic text as well as the experience of concrete mentorship and co-authorship in a mono-choreodrama. The authorial project is enhanced by a cultural theme of Salome as a dance performer, and also by the drama character from the drama legend of the same name written by Miroslav Krleža, as well as by a long-standing interest in the works of the eminent writer which were suppressed in the Yugoslav cultural public. The research also included the analysis of the literarytheoretical reception of the play, the comparison and the selection of certain parts of Salome's text from Krleža's versions preserved in manuscripts, which all have led to forming a dramaturgically independent authorial unity of the text and along with it - 
a practical implementation in the hall through the process of a bodily acquisition and reshaping of the material.

Keywords: Miroslav Krleža, Salome, eloquent dance performer, body, stars

\section{Uvod}

Prvo što želim naglasiti u osvrtu na mentorski rad (a mentorstvo je pozicija koja nesumnjivo zahtijeva umjetničko-znanstveni diskurs) sa Selmom Mehić na njezinu diplomskom radu iz glume vezanom uz čitanje i transformaciju drame Miroslava Krleže Saloma u monokoreodramu Krležina Saloma / Rekvijem za mladog umjetnika jest povijesna pozicija i uloga umjetničkih akademija kao (posljednjih ili samo rijetkih?) oaza umjetničke autonomnosti, rijetkog zaštićenog prostora slobode umjetničkog istraživanja jednako za studente i nastavnike. Tijekom cjelogodišnjeg rada na projektu potvrdilo mi se uvjerenje koliki je privilegij dobiti povjerenje, pažnju, vrijeme i strast talentiranog mladog čovjeka, i kolika je odgovornost u održavanju balansa između vodstva, prijedloga i uputa i njegovanja i podržavanja umjetničke (i ljudske) osobnosti i osebujnosti. Selmu sam prepoznala od prve godine preddiplomskog studija. Njezina intelektualna radoznalost, kao i ozbiljnost i posvećenost bavljenja tijelom, plesom i pokretom te istraživanje mogućnosti ispreplitanja tjelesnih i glumačkih principa bila je rijetka i razvidna. Spadala je u mlade glumice kod kojih je riječ nosila tjelesnu uvjerljivost i duboko, osjetljivo pokriće. Za monolog iz Krležina dramskog opusa koji je bio uvjet za prijemni ispit za diplomski studij glume na Umjetničkoj akademiji u Osijeku pripremila je Salomu kojoj su, kako je obrazložila, kretanje i pokret upisani kao dramska odrednica lika. Njezina je izvedba bila iznimno inspirativna i tada smo negdje već zaključile da ćemo zajednički nastaviti istraživanje na tu temu. Selmu je Krležina drama privukla „intuitivno, dramski i emotivno “1, a ja sam se već neko dulje vrijeme „spoticala" o istu temu tijekom svojih istraživanja u prostorima povijesti plesa. Naime, u solističkim koncertima predstavnica plesnog modernizma (od početka 20. stoljeća) Saloma kao da je bila obavezni naslov (između ostalih je i Mia Čorak Slavenska imala Salomu na svom repertoaru ${ }^{2}$, to je bio dio pobjedničkog programa u Berlinu 1936. i kasnije ju je godinama igrala).

${ }^{1}$ S. Menić: Krležina Saloma, diplomski rad iz glume. Osijek, UAOS, 2015, s. 1.

${ }^{2}$ Mia Čorak Slavenska (Slavonski Brod 1916. - Los Angeles 2002.) Prva hrvatska primabalerina i jedna od najvećih svjetskih balerina 20. st. Kao dvadesetogodišnjakinja je razmišljala napraviti Salomu i kao veće scensko djelo, „,kojoj ne želim dati samo psihološku notu, jer želim stvoriti Salomu gledanu kroz zrcalo sadašnjosti, kao neki memento“. Više u: M. Đurinović, Z. PoDkovac: Mia Čorak Slavenska. Zagreb 2004. 
Kao izvrsna studentica glume, Selma je željela doličnu završnicu svog studija, a ja sam uz to imala ideju i želju da joj pripremimo „popudbinu“, neka vrsta "miraza“, odnosno osobne iskaznice izvođačke vještine i umjetničkog stava s kojom će se predstaviti pri ulasku u svijet profesije. Diplomski ispit velika je prekretnica za mladu glumicu/glumca: nakon pet godina zaštićenog prostora Akademije ona izlazi na tržište, gdje se mora potvrditi izlažući svoj jedini, ali i jedinstveni „,kapital“.

\section{Počeci rada}

Ni Selma ni ja na početku radnog procesa nismo imale, niti smo htjele imati neku „redateljsku“ scensku viziju kako bi i u kojoj formi naš rad u konačnici trebao izgledati. U rukama smo imali dva rada Miroslava Krleže: dramu Saloma, objavljenu u Legendama (1963.) i pjesmu Saloma, pjesnički fragment iz eposa Smrt Ivana Preteče (1918.) koju smo već ranije scenski oblikovale za nastup u okviru projekta Words can dance 3 i koja je na neki način usmjerila naš pogled na dramsku Salomu i - u konačnici ostala kao neka vrsta uvertire u koreodramu. Stihovi iz pjesme:

A miris zemlje - to je lijek bolnog nemira.

A miris zemlje - to je prezir svemira.

Za zvijezdom naričeš, tužna kraljevno -

Još nikad nitko nije ko ti bolno disao,

O kraljevno, čemu viši smisao?

s naglaskom na tužnoj kraljeoni potirali su se s frivolnom mačkom čije se reakcije i stavovi tijekom drame mijenjaju, činilo nam se - izvan glumačke motivacije i dramske logike. Da bismo dokučili tko je Krležina Saloma, trebalo se probiti kroz njezinu rječitost i nadmudrivanje s Kajom Antonijem i dva Helena. Zanimalo nas je što će se dogoditi kad je očistimo od gustih slojeva krležijanski elokventnih likova, kad ostane sama? No, oslobođena od dosadnih filozofa, generala, umjetnika i farizeja ${ }^{5}$, cijelog tog lažnog dvorskog lupanara, Krležina rječita plesačica-kraljevna kao da je prodisala. Konačno se mogla protegnuti u vertikali otvorenoj prema zvijezdama. Dobila je fizički prostor koji joj je omogućio snažni i skladni kinestetički osjećaj, ali i neku

${ }^{3}$ Događanje u formi književno-plesne izložbe povodom Međunarodnog dana plesa održano je u organizaciji plesne udruge CorpArt i Umjetničke akademije u Osijeku 29. travnja 2014. u Galeriji Kazamat u Osijeku.

4 Saloma, "Savremenik" 1918.

${ }^{5}$ Drama počinje Salominim uzvikom: „Ništa! Dosadni ste kao mokri psi!...”. 
duhovnu prozračnost. Selma je ubrzo iskoreografirala minijaturu - pokretom je "prevela" tekst svoje/Salomine životne priče (hamletovska pozicija na dvoru, dodatno zakomplicirana incestom): „Moj kraljevski poočim, uzvišeni Tetrarka, hoće da zakolje moju majku da bi me mogao okruniti judejskom krunom [...] Utješno je pri tome samo to što moja gospođa majka tvrdi da moj kraljevski otac nije bio meni tata, nego da mi je rođeni tata moj stric Tetrarka..."6 - u tjelesnu sekvencu i taj zgusnuti plesni materijal simboličnih akcija i gesta ostao je tjelesnim temeljem cijele predstave kroz koju su se kasnije provlačili već uspostavljeni i poznati motivi. Tako je lik Salome $\mathrm{u}$ interakciji teksta i pokreta počeo poprimati autentične, nove obrise. No, ono što nam je izmicalo, a što ni scenska interpretacija nije rješavala bila je poanta; nedostajao je razlog preobrazbe, ono nešto što bi osmislilo cjelinu prožimajući je osobnim i umjetničkim stavom kao razlogom scenskog uprizorenja. Trebalo je zagrabiti šire i dublje, vratiti se na izvore. Tko je u našem/ europskom kulturnom nasljeđu Saloma? Koji je Krležin obrat? I najvažnije: zašto je intuitivno prepoznajemo tako bliskom i suvremenom?

(Kao slučajno, baš u to vrijeme, u Galeriji likovnih umjetnosti u Osijeku postavljena je izložba Osječanina Bele Čikoša Sesije koji je 1919. dovršio svoju Salomu. Naravno da je od svih njegovih djela baš Saloma bila na plakatu i gledala nas s reklamnih panoa.)

\section{Znanstveno-teorijska podrška i istraživanje rukopisa}

Rješenje za naše scensko uprizorenje počelo se nazirati kroz neke znanstvene radove na temu Krležine Salome. Ključni je trenutak bio susret s tekstom Suzane Marjanić: Krležin feminizam ili Saloma + Melanija, to sam ja! (časopis „Kazalište“, 2013.), zatim, također vrlo važni, tekst iste autorice: Tri režijska rukopisa: primjer kazališta političke alegorije, kazališta socijalne akcije i post/ esteticizma (zbornik Krležinih dana u Osijeku, 2012.) te radovi i promišljanja Mate Lončara i Josipa Donata, kao i jedna crtica iz Povijesti hrvatske književnosti S. P. Novaka. Sve zajedno je rezultiralo snažnim impulsom da se vratimo na početak, što nas je odvelo u arhivu Nacionalne i sveučilišne knjižnice u Zagrebu, gdje smo dobile na uvid rukopise Salome iz ostavštine Miroslava Krleže. U rukama smo imale piščeve zapise, intimne otiske, utiske i misli! Pod naslovom Saloma nalazilo se više inačica, od prvog rukopisa iz 1914. u koji su upisane kritičke primjedbe ravnatelja Hrvatskog narodnog kazališta Josipa Bacha (koji je mladog Krležu više puta odbio), do niza klasificiranih autografa koje čine fragmenti, dijalozi, stihovi, didaskalije, asocijacije; zapisano pisaćim strojem ili rukom, uredno ili na papirićima, uz prekrižene

\footnotetext{
${ }^{6}$ M. KrležA: Legende. Čakovec 2002, s. 256.
} 
i prepravljane riječi... Ukratko, sve je upućivalo na nesigurnost umjetnika koji traži riječi, ali i smisao, pisca koji je, uostalom, kako znamo, temu Salome i njezine sudbine promišljao pola stoljeća, bitno mijenjajući njezin lik. U tim fragmentima našle smo Salomine rečenice koje su nam nedostajale i koje su se savršeno smisleno uklapale u našu dramaturgiju njezina monologa, tako da je konačni tekst Selmine monodrame formiran iz više Krležnih Saloma, pri čemu ni jedna riječ nije promijenjena.

\section{Mladi umjetnici u starom svijetu}

Miroslav Krleža, mladi pisac, ili bolje pjesnik, bio je Selminih godina kad je zamislio dramsku legendu Salomu i u njoj je puno njegove „dvadesetogodišnje mjesečine" i buntovništva. Njezina čežnju za zvijezdama čežnja je za oslobađanjem od pragmatički izvitoperene jave, za puninom istinskog i iskrenog bivanja; ona je prometejska, razapeta između nedostižnog, ali naslutivog neba i tople, meke, zemaljske, tjelesne puti. „Zašto ne bi naš život ispunili nama? / Našim poletima i našim mislima? ${ }^{\prime \prime}$.

Josip Bach sredinom lipnja 1914. argumentirano je odbio mladog pisca riječima: „Vaša je Saloma zbilja nova. Samo nažalost nije drama. Odviše govore Saloma i Johanaan. I to nedramatski govore“. I to je bila istina. Ipak, Krležina heroina je tada rođena, bez obzira na kasnije velike i stalne preinake, tijekom kojih će na primjer Johanaan posve ostati bez teksta. A Krležina Saloma jest "nova" i suvremenija, provokativna i prkosno preoblikovana u odnosu na onu „staru“, europskim umjetnicima tako privlačnu fatalnu i grešnu ženu.

\section{Saloma}

U zagrebačkim Narodnim novinama od 22. travnja 1913. objavljen je nepotpisani članak koji se bavi genealogijom Salominog lika. Te iste godine (kada nastaje i Meštrovićeva Saloma), izlaze Matoševe Pečalbe u kojima je njegov esejistički osvrt Isadora Duncan ${ }^{8}$ posvećen „divnoj ženi“ kojoj je ples „njezin govor, njen genij“. Matoša očarava mladenačka čistoća, nepatvoreni zanos i - ljepota tijela koje je izloženo „u koprenastoj nagosti“ na neki posvećeni, slavljenički, antički, način i u njoj vidi nježnost i snagu; ona je "odista sve: slika i simbol ovog svijeta [...] Ona je harmonijski stožer [...] oživjela pjesma, suza i radost..."9. Iste 1913. godine, Krleža počinje pisati Salomu koja je mlada

\footnotetext{
7 II autograf (1914).

8 A.G. Matoš: Isadora Duncan. U: Sabrana djela, svezak V. Zagreb 1973, s. 234-239.

${ }^{9}$ Lourenence Louppe u uvodu svog fundamentalnog djela Poetika suvremenog plesa govori o plesu s početka 20. stoljeća kao jednoj od bitnih figura epistemološkog reza koji je
} 
umjetnica superiorne inteligencije, hrabra i slobodna, otvorenog sklada duha i tijela; istovremeno plesačica i kraljevna koja traži razlog i način preživljavanja na opako iskvarenom i po život opasnom tzv. "Judejskom dvoru“"

Povijesno, Saloma je kći je Heroda Filipa i Herodijade. Polubrat njezina oca, njen stric Herod Antipa, bio je tetrarh Galileje i Pereje od 4. pr. Kr. do 39. p. Kr. Sačuvan je novac s njenom slikom, a povijesnim je istraživanjem utvrđeno da se dva puta udala i da je u drugom braku imala troje djece. Njezino spominjanje u Novom Zavjetu u Markovu i Matejevu evanđelju kao fatalne plesačice koja će, prema majčinoj uputi, u zamjenu za nastup tražiti glavu Ivana Krstitelja temelji se na zapisima židovskog vojskovođe i povjesničara Josipa Flavija. Kako je ušla u Bibliju, tako njezin lik uzbuđuje umjetničku maštu kršćanskog svijeta (nalazimo je i na oltarima!), a s vremenom dobiva mitsku dimenziju. Njezino je ime u memoriji zapadne civilizacije obilježeno grešnom putenošću: razgolićena, putena plesačica Saloma na tanjuru nosi svečevu glavu. Ima li znakovitije slike u crkvenoj ikonografiji? (I našoj civilizaciji koja počiva na antičkim, biblijskim i mitskim motivima.) U njoj se ogleda nepremostiva dihotomija tijela i duha/uma, grešnog i svetog: ženskog i muškog.

Eugenio Barba, utemeljitelj kazališne antropologije, primijetio je da je za našu, zapadnu kulturu karakteristično namjerno produbljivanje jaza izoštravanjem razlika između plesa i drame, što rezultira prazninom koja glumca vuče ka negiranju tijela, a plesača prema samodostatnoj tjelesnoj virtuoznosti. Ta „specijalizacija“ i polarizacija vezana uz civilizacijsku dihotomiju duha i tijela, zamagljuje zajedničke korijene i smisao kazališta. A suvremena kazališna pedagogija ima zadatak popunjavanja tih praznina osviještenim insistiranjem na prepoznavanju odnosa tijelo/um, njihove međuzavisnosti i usklađenosti. Tko god se bavio ili barem ozbiljnije pratio plesnu umjetnost, zna kolike su i koliko duboke predrasude spram plesa, kako one civilizacijske tako i specifično nacionalne. Civilizacijske u smislu Zapadne kulture i njezina institucionalizma i tumačenja i provedbe kršćanstva, tipa: U početku je bila Riječ, Cogito ergo sum, tijelo kao tamnica duše i slično... Taj prijepor uma/ duha i tijela upisan je u memoriju zajednice u smislu superiornosti intelekta i nevjerojatno je kako i u današnje vrijeme mnogih civilizacijskih pomaka upisanih u suvremene ustave kontinuirano provaljuje kao arhetipski obrazac pod stalno novim perfidnim maskama.

I u tom smislu Oscar Wilde nije ponudio ništa novo, iako je njegova Saloma nesumnjivo najpoznatija književna interpretacija lika. Ona je počet-

uzdrmao sve struje mišljenja naše epohe, kako u humanističkim znanostima tako $i$ u političkim i filozofskim pristupima. Riječ je o tome da tijelo u pokretu koje je istovremeno subjekt, objekt i instrument spoznaje budi drugačiju percepciju i spoznaju svijeta, nov način osjećanja i stvaranja, a obnovljena percepcija djeluje i na gledatelja i na plesača u smislu prepoznavanja vlastitih reakcija, pronicljivosti, dubljih osjeta estetskog doživljaja. 
kom 20. st. vrlo u modi, a Zagreb ne zaostaje za Europom: Josip Bach (onaj koji je kasnije odbio našeg nadobudnog pjesnika) režira je već 1905., a Straussova opera po istom libretu postavlja se 1915. Ali mladi Krleža je raskrinkava kao dekadentnu, romantičarsku fatalnu ženu, vampiricu morbidne erotike. Uistinu, Wildeova Saloma nas nije nimalo privlačila, dapače složile smo se u stavu da taj ženski lik nosi nešto odbojno i uvredljivo simplificirano. Zato nam se činio vrlo znakovit i dirljiv Krležin obrat teme najavljen već u njegovoj prvoj tiskanoj drami, Legenda (1914.): kad Sjena prepričava Kristu (Wildeovu) Salomu, na kraju dodaje detalj: suzu koja je kapnula iz svečeva oka na tanjur. Suzu čežnje, zauvijek propuštenog trenutka ljepote.

Krležina Saloma lik je zvjezdane perspektive beznadno zalijepljen o zemlju. Usamljena, tužna kraljevna okružena je „lažljivcima, glupanima, ulizicama i ubojicama“ i na žalost, nitko, pa - u konačnici razočarano shvaća - ni prorok (koji je na trenutak dobio njezino povjerenje kao jedini čovjek koji se nije bojao govoriti istinu) ne može joj pomoći da se izvuče iz šekspirijanski krvavog Dvora. Ona tek sluti, vjeruje da postoji to nešto više, mogućnost protezanja tjelesnih mogućnosti do onostranog, i ta čežnja napinje osjetilni ambijent ${ }^{10}$ kože.

Kako plesati na „pasjem otoku“? Kod Krleže plesati znači nešto drugo, a ne erotski spektakl skidanja sedam velova, što je zapravo sofisticirani izraz za profinjenu izvedbu striptiza. Ovdje je Ples znak božanskog nadrastanja tjelesnog i dohvaćanje zaumnog za razliku od onog tjelesnog koje nas „ponizuje do četveronožnosti“! Antibiblijski i antiwildeovski - Krleža potpuno odustaje od Plesa sedam velova. Mi smo pak, kao neki „hommage“ plesu koji je postao sinonim Salomina očaravajućeg umijeća, utkale u tekst i pokret igru sa sedam marama različitih boja koje su jedini rekvizit i prozračni produžetak njezine nehajne, nestašne ili zavodljive ili sanjarske ili sarkastične ženstvenosti.

\section{„Jahve, za koga pričaju ... da pleše nikad viđene čudne plesove ${ }^{\prime 11}$}

Dok je svijet Istočne kulture nastao iz kozmičkog plesa stvaranja boga Šive, u početku naše Zapadne civilizacije bila je - Riječ. Mučilo je to i Goetheova Fausta; moćni um se opirao dogmi u žudnji punine života... tražio je točniji izraz za to nešto, prvotno, pokretačko; prvi titraj, impuls, pokret. "Gdje da te zgrabim, silna prirodno", zavapio je Faust. A priroda je tu, tako blizu, unutra. To može biti i Riječ koja je, uostalom, već i u Ivanovu evanđelju: tijelom postala. Duh, znanje, osjet, ideja, emocija sve to ne postoji bez utjelovljenja. Umjetnost je čežnja duha za oblikom, utjelovljena misao. A to je,

\footnotetext{
${ }^{10}$ L. Louppe: Poetika suvremenog plesa. Zagreb 2009, s. 68.

${ }^{11}$ II autograf (1914).
} 
također, prema Badiouu - ples. Iako se filozof zaigrao u spekulaciji i iz koje slijedi da ples nije umjetnost jer je znak mogućnosti umjetnosti kakva je upisana $u$ tijelo ${ }^{12}$, mora se priznati zavodljivost njegove misli. Ples je znak sposobnosti tijela za umjetnost. Ples je kao metafora misli, kao neupisana, nezabilježena pjesma. Uistinu, ples možemo smatrati poezijom tijela. Tijela bivaju dirnuta, prožeta onim što čine ili onime što čitaju $u^{13}$.

Prema uvodnoj didaskaliji Saloma je "naga, zaogrnuta srebrnim velom“, znači izloženog tijela, i s tom nekonvencionalnom izloženošću ona se igra, zadirkuje okupljene muškarce (predstavnike različitih društvenih moći), kritizira ih i kroz svoj sarkazam - ogoljuje. Najednom su oni goli: „oni koji ne sanjaju", "koji kupuju svoje misli i misaone sisteme po dućanima pomodne robe“, a njihovi pogledi "plaze po njezinim nagim nogama“. Dosadni i predvidljivi! A njezino prirodno, izloženo tijelo nije grijeh, nego ljepota božjeg djela. "Samo ljudsko tijelo može da dočara ljepotu božjeg djela. Ništa pod nebom nije ljepše od ljudskog tijela. Kipovi su samo sjenka te ljepote." Kazuje Saloma zanijemjelom proroku, čime Krleža kao da ponavlja misao ostarjelog pisca Gustava von Aschenbacha (T. Mann, Smrt u Veneciji, 1912.) zatečenog čulnim manifestacijama života "na rubu modrila“, zatravljenog spoznajom simbolike savršenog ljudskog tijela kao božanskog kipa: „Jest, samo se pomoću tijela može uzdignut do višeg sagledanja“.

Svjesno smo odbacile kasniju Krležinu interpretacije dramske legende u kojoj je Saloma hiperkulturna Skepsa, a Johanaan primitivni nacionalni nagon - gdje pobjeđuje skepsa, kao što nas nije zanimala mimeza povijesnog političkog trenutka u kojem se Hrvatska prepoznaje kao carska provincija Judeja, a lažni proroci i farizeji imaju imena domaćih političara. Zamorene svakodnevnim aktualnim inačicama priča s Judejskog dvora, zaključile smo sa Salomom: „Dosadno!“ i sa njom pogledale u zvijezde, u daljine.

Oh, da nisam žena! Da nisam sada žena, ustala bi i okupala bi se u moru. Od svega bi se okupala! I pošla bi. Daleko bi pošla! Tamo! Do horizonta! I dalje! I dalje! [...]

I ne bi stala na Gangesu kao Aleksandar. Dalje bih pošla...14.

Slijedeći njezine potencijale i snove, svjedočili smo dilemama mlade žene, o smislu preživljavanja, kratkotrajnoj nadi u Proroka, i intimnom porazu.

I dok na kraju Wildeovu Salomu taj isti pokvareni dvor s gnušanjem ubija, Krleža svoju kraljevnu vraća u realnost. Kao da su se tijekom zajedničkog odrastanja oboje prizemljili. „Živjeti tek treba znati!“ izgovara više Krležinih

\footnotetext{
12 A. Badiou: Ples kao metafora misli. „Kretanja“ 2009, br. 12, s. 12-17.

${ }^{13}$ L. Louppe: Poetika suvremenog plesa. Zagreb 2009, s. 22.

14 A 158.
} 
likova. Pa kad se već pristaje na životne kompromise u toj skandaloznoj pustinji duha - treba živjeti na najvišoj, što je moguće, nedodirljivijoj točki. Krležina Saloma udaje se za Tetrarku, kraljevska svadba je rekvijem za mladu umjetnicu, ali osigurava život i status kraljice; a buntovni je pisac prihvatio najviši državni status i doživotnu sigurnost na Titovu "dvoru“.

\section{Epilog (za mlade kazališne umjetnice/umjetnike)}

Kroz dugi period dominacije Riječi i Misli nad tjelesnim i osjetilnim otvorila se pukotina u koju se savršeno smjestila potrošačka svijest, u smislu sve dublje podjele između izvođača i onih koji mogu i hoće platiti, ali pri tome zahtijevaju poštivanje njihovih pravila. I da ih se zabavi. (Medo, pleši!) Od mladih se umjetnika (i) danas očekuje da šute i otrpe različite pokušaje manipulacija i prezentaciju neke tuđe moći. Stoga pozicija nastavnika na umjetničkoj akademiji nosi izazov poticanja kreativnosti i hrabrosti osobnog stava, ali i dužnost podržavanja i zaštite dostojanstva tako izloženih, osjetljivih tijela koja žele i moraju ustrajati u osnovnom umjetničkom zadatku: biti "čarobno" ogledalo, uznemireni odraz stvarnosti.

\section{Aneks}

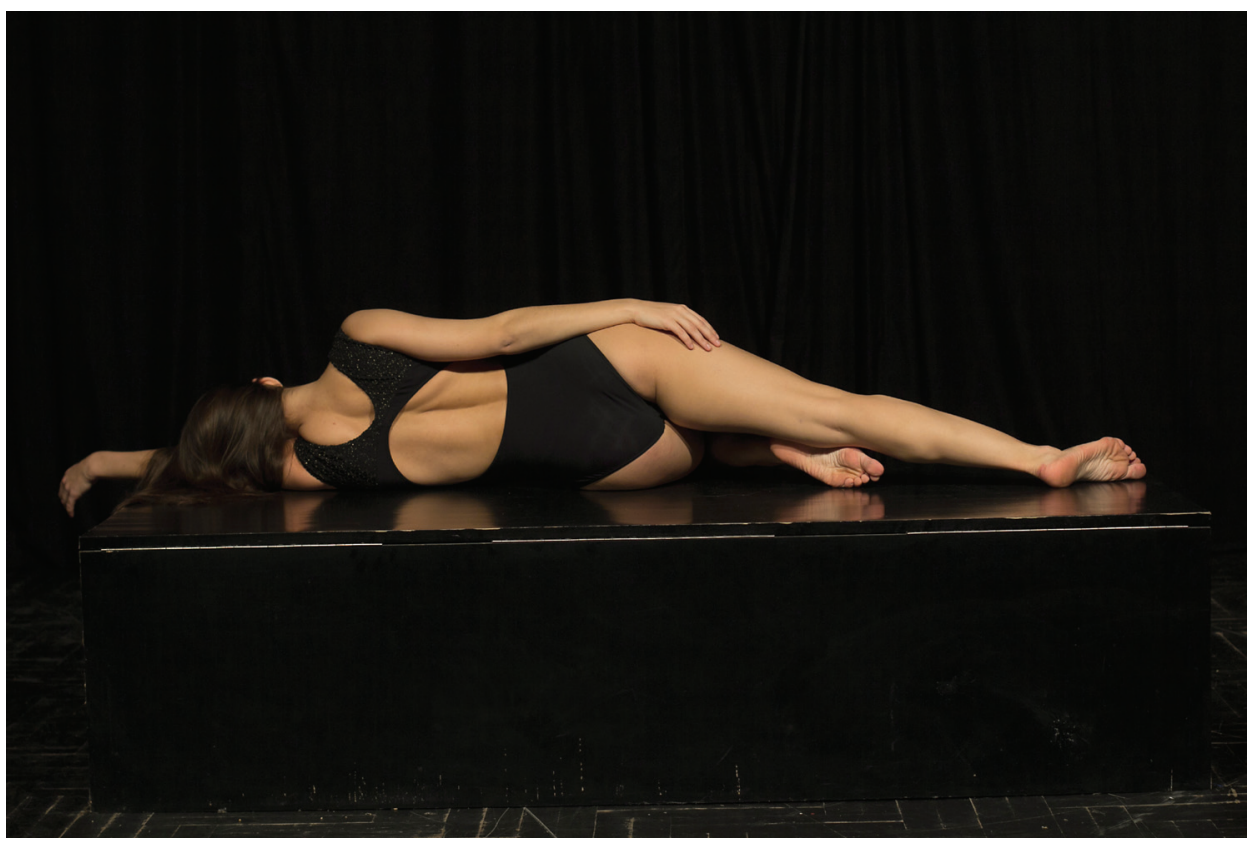

Fot. 1. Selma Mehić, Krležina Saloma, foto: Kristina Marić 


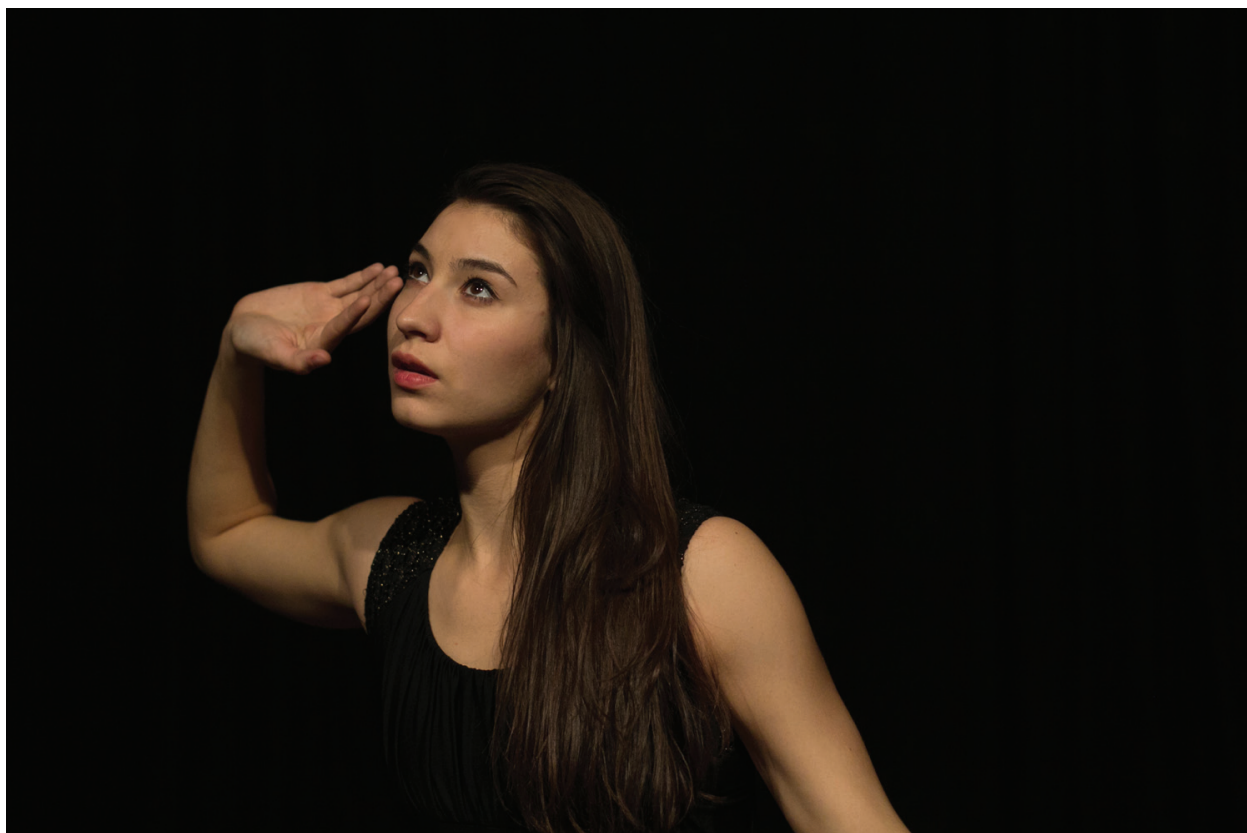

Fot. 2. Selma Mehić, Krležina Saloma, foto: Kristina Marić

\section{Literatura}

Autografi M. Krleže pohranjeni u arhivu Nacionalne i sveučilišne knjižnice u Zagrebu pod naslovom Saloma.

Badiou A.: Ples kao metafora misli. „Kretanja“ 2009, br. 12.

Donat B.: O Miroslavu Krleži još i opet. Zagreb 2002.

KrLežA M.: Legende. Čakovec 2002.

Louppe L.: Poetika suvremenog plesa. Zagreb 2009.

Lončar M.: „Saloma“ Miroslava Krleže. U: Miroslav Krleža. Beograd 1967, s. 249-275.

Marjanić S.: Krležin feminizam ili Saloma + Melanija, to sam ja!. „Kazalište” 2013, br. 53/54, s. 96-106.

Marjanić S.: Fragmenti Salome $u$ Davnim danima: Saloma isprva kao Hrvatica, a iz perspektive Pijane novembarske noći 1918 kao trikolorna esheazijska Ravijojla. U: IDEm: Glasovi davnih dana, transgresije svjetova u Krležinim zapisima 1914-1921/22. Zagreb 2005, s. 101-141.

MARJANić S.: Tri režijska rukopisa: primjer kazališta političke alegorije, kazališta socijalne akcije i post / esteticizma. U: Kazalište po Krleži. Zagreb-Osijek 2013, s. 171-187.

Novak S. P.: Povijest hrvatske književnosti; Od Baščanske ploče do danas. Zagreb 2003.

Pavlović C.: Dekadentna zavodljivost Krležine Salome. U: Kazalište po Krleži. Zagreb-Osijek 2013, s. 37-50. 